\title{
Adaptive Gluconeogenesis in Preterm and Term Rabbits
}

\author{
LEROY C. MIMS \\ Section of Neonatology, Department of Pediatrics, Medical College of Georgia, Augusta, Georgia USA
}

\begin{abstract}
Summary
Carbohydrate metabolism in the developing rabbit was investigated for deficiencies that may be responsible for the failure of many preterm $\left(28 \frac{1}{2}-291 / 2\right.$ day) animals to survive the first hours of life. The preterm animal shows an inability to reverse glycogenolysis or initiate gluconeogenesis from lactate or alanine in the first hours of life. This impairment, coupled with $50 \%$ less liver glycogen stores than the term animal, places the preterm animal at jeopardy for energy substrate early on in life. Unexpected was the early, rapid conversion of glycerol to glucose by the preterm animal. This ability seemed to be the primary difference in carbohydrate metabolism between the surviving and nonsurviving preterm rabbit.
\end{abstract}

\section{Speculation}

Impaired glyconeogenesis from lactate and alanine in the preterm animal coupled with active gluconeogenesis from glycerol suggests that substrates from lipolysis may be very important for early adaptation. Preterm animals endowed with limited fat stores, thus, minimal available glycerol, would be incapable of survival.

In recent years, the development of mammalian fetal and neonatal carbohydrate metabolism has been the subject of intense investigation particularly in rats $(1,3,5,10-12,17,19-21)$. A number of studies have also been conducted in the neonatal pig $(7,9,18)$, guinea pig (1), and human (2).

Because no studies of term and preterm rabbits have been done except to determine hepatic glycogen content, we have examined carbohydrate metabolism and stores in preterm rabbits for deficiencies that may be responsible for the failure of many of these animals to survive the first hours of extrauterine life. Preterm and term rabbits were studied at birth and throughout the first hours of life. We compared the results from the two groups of animals and attempted to identify those aspects that appear to be factors in the inability of some preterm rabbits to survive beyond the first few hours, while the full term rabbit is usually successful in the adaptive process. A portion of this data has been presented previously (22).

\section{MATERIALS AND METHODS}

All enzymes, substrates, cofactors, and Dowex-1x8 (Chloride form) 200-400 mesh, ion exchange resin were purchased from the Sigma Chemical Company, St. Louis, MO. Glucostat (regular) was purchased from the Worthington Biochemical Corporation, Freehold, NJ.

Sodium L-[1- $\left.{ }^{14} \mathrm{C}\right]$ lactate, $(4.7 \mathrm{mCi} / \mathrm{mmole})$; [U $\left.{ }^{14} \mathrm{C}\right]$ glycerol, $(7.4$ $\mathrm{mCi} / \mathrm{mmole}) ;\left[\mathrm{U}-{ }^{14} \mathrm{C}\right]$ alanine, $(156 \mathrm{mCi} / \mathrm{mmole}) ;$ and $\mathrm{L}-\left[1-{ }^{14} \mathrm{C}\right]$ alanine, $(58.2 \mathrm{mCi} / \mathrm{mmole})$ were obtained from New England Nuclear, Boston, MA. Insta Gel was pruchased from the Packard Instrument Company, Downers Grove, IL. Distilled, deionized water was used throughout this study.

\section{EXPERIMENTAL ANIMALS}

New Zealand White rabbits, (Cottonwood Rabbitry, Coweta, OK) bred under direct observation, were killed by injection of 50 $\mathrm{ml}$ air into a marginal ear vein. The fetuses were quickly removed from the uterus and placed in a brooder at $33^{\circ}$. Litters of the same gestational age were mixed. The 30.5 and 28.5 day gestational age rabbits were defined as term and preterm, respectively. Only surviving animals were studied, because death in the preterms occurred at delivery or immediately thereafter. Those dying after the study period were considered beyond the adaptive period and not included.

\section{INJECTION OF ${ }^{14}$ C-LABELED PRECURSORS}

Intravenous injection of ${ }^{14} \mathrm{C}$-labeled precursor $(0.5 \mu \mathrm{Ci})$ without dilution was accomplished by making an anterior-to-posterior midline incision through the scalp, exposing the sagittal vein and injecting directly into the vein with a $50 \mu$ l Hamilton syringe. This route seemed more appropriate for our needs than intraperitoneal injection (Figs. 1, 2, 3).

\section{COLLECTION AND EXTRACTION OF WHOLE BLOOD}

After decapitation of the fetuses, whole blood (about $1 \mathrm{~g}$ ) was collected in a weighed, screw cap test tube, which contained $1 \mathrm{ml}$ of $10 \% \mathrm{HClO}_{4},(\mathrm{v} / \mathrm{v})$. The acid insoluble material was removed by centrifugation at $0^{\circ}$ and the resulting pellet was extracted twice with $1 \mathrm{ml}$ portions of $10 \% \mathrm{HClO}_{4}$. The combined supernatants were neutralized with $\mathrm{KOH}$ and centrifuged. The supernatant was stored at $-20^{\circ}$ after recording the volume.

\section{DETERMINATION OF WHOLE BLOOD GLUCOSE AND LACTIC ACID}

Glucose and lactic acid were assayed by a modification of the method of Mattenheimer (8) in which Tris- $\mathrm{HCl}$ was substituted for triethanolamine buffer in the glucose assay.

\section{DETERMINATION OF GLUCOSE SPECIFIC RADIOACTIVITY}

Dowex-1x8, in the acetate form, was prepared by conversion to the hydroxide form, using $\mathrm{NaOH}$, followed by conversion to the acetate form using acetic acid. A $0.5 \times 7.0 \mathrm{~cm}$ column of this resin was charged with the remaining neutralized $\mathrm{HClo}_{4}$ extract. Glucose was washed from the column with approximately $5 \mathrm{ml}$ water and was converted to glucose-6-phosphate in a mixture which contained $2.5 \mu$ moles Tris- $\mathrm{HCl}$ (p 7.6), $1 \mu$ mole ATP, $1 \mu$ mole $\mathrm{MgCl}_{2}$ and approximately 1 unit of hexokinase (E.C. 2.7.1.1). Incubation of standard glucose in this system resulted in the conversion of greater than $90 \%$ of the glucose to glucose-6-phosphate within $15 \mathrm{~min}$ at room temperature.

Glucose-6-phosphate was isolated from the neutral and cationic species by using a $0.5 \times 7.0 \mathrm{~cm}$ column of Dowex- $1 \times 8$, chloride form, charged with the entire glucose-6-phosphate synthesizing mixture. The column was first washed with water and then with $20 \% \mathrm{HClO}_{4},(\mathrm{v} / \mathrm{v})$ to elute the glucose-6-phosphate from the resin. 


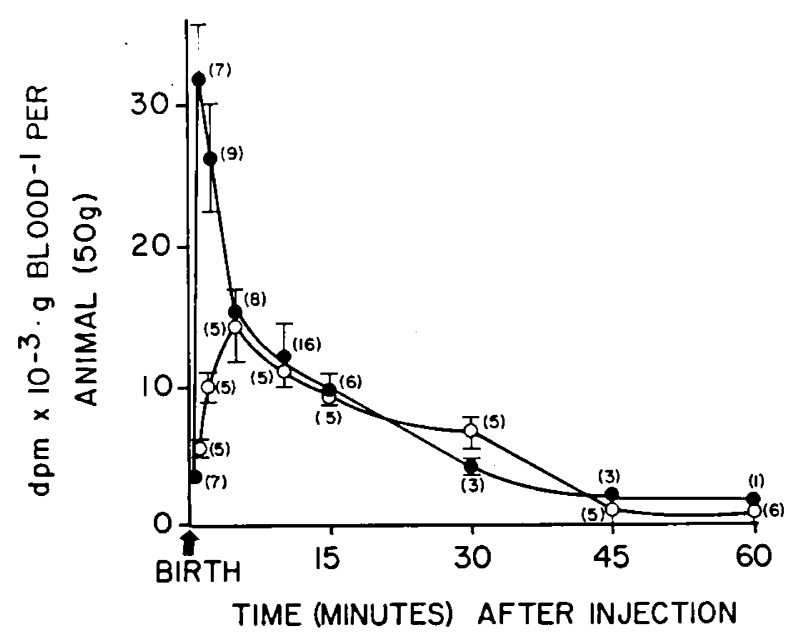

Fig. 1. Total radioactivity in neutralized $\mathrm{HClO}_{4}$ extracts of whole blood $\left(\mathrm{dpm} \times 10^{-3} \cdot \mathrm{g} \mathrm{blood}^{-1} / 50 \mathrm{~g}\right.$ animal) as a function of time after injection (min). $0.5 \mu \mathrm{Ci}$ of $\mathrm{L}-\left[1-{ }^{14} \mathrm{C}\right]$ lactate in $50 \mu \mathrm{l}$ was injected either iv or ip into 30.5 day rabbits 20 min after delivery. All data are expressed as the mean \pm SEM or the mean only. The number of animals is in parentheses. (- - iv injection, - $\mathrm{O}$ - ip injection).

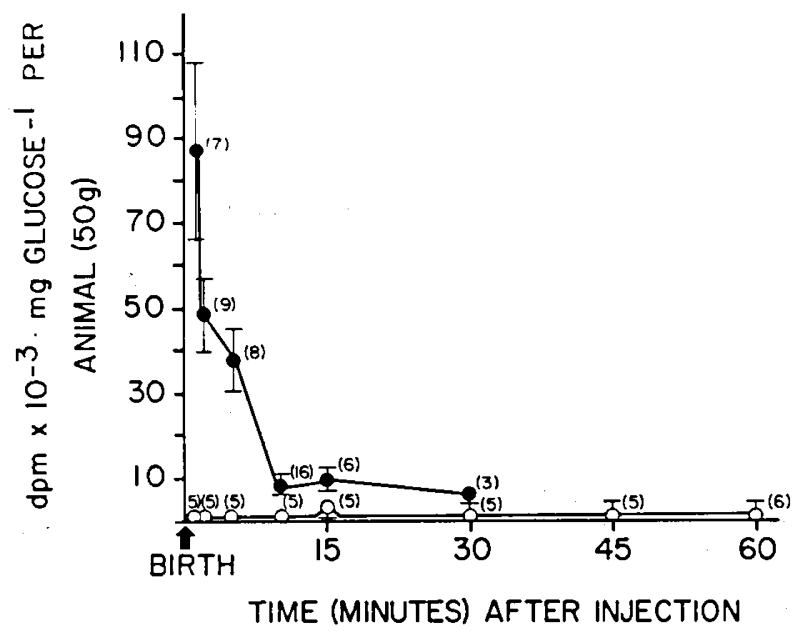

Fig. 2. Whole blood glucose specific radioactivity $\left(\mathrm{dpm} \times 10^{-3} \cdot \mathrm{mg}\right.$ glucose $e^{-1} / 50 \mathrm{~g}$ animal) as a function of time after injection (min). $0.5 \mu \mathrm{Ci}$ $\mathrm{L}-\left[1-{ }^{14} \mathrm{C}\right]$ lactate in $50 \mu \mathrm{l}$ was injected either iv or ip into 30.5 day rabbits $20 \mathrm{~min}$ after delivery. (- - iv injection, $-\mathrm{O}_{-}$ip injection).

The $\mathrm{HClO}_{4}$ was neutralized to $\mathrm{pH} 7$ with $\mathrm{KOH}$ and $\mathrm{K}_{2} \mathrm{CO}_{3}$ and the sample was chilled. After centrifugation, a $1.0 \mathrm{ml}$ aliquot was mixed with $3.5 \mathrm{ml}$ water and $10 \mathrm{ml}$ Insta Gel. Radioactivity was determined in a Packard Tri-Carb Liquid Scintillation Spectrometer, Model 3380. For the calculation of glucose specific radioac- tivity, only those samples whose radioactivity was at least twice the background count rate were used. The glucose-6-phosphate in $25 \mu \mathrm{l}$ of the neutralized material was determined in a system which contained $37.5 \mu$ moles Tris- $\mathrm{HCl}$ (p 7.5), $0.24 \mu$ moles NADP ${ }^{+}$and glucose-6-phosphate dehydrogenase. The final volume was 320 $\mu \mathrm{l}$.

\section{QUANTITATION OF HEPATIC GLYCOGEN}

Glycogen was determined in $10 \%(\mathrm{w} / \mathrm{v})$ aqueous liver homogenates using amyloglucosidase (E.C. 3.2.1.3) and the Worthington Glucostat reagent kit as described by Roehrig and Allred (13).

\section{BIOMETRIC CONSIDERATIONS}

The data have been expressed as the mean \pm 1 SE with $(n)$ indicating the number of animals. The statistical significance between means at the $5 \%$ level was determined by using Cochran's two-tailed test of significance because the variances of the groups of data were unequal (15).

\section{RESULTS}

\section{WHOLE BLOOD GLUCOSE}

Figure 4 shows the whole blood glucose concentration in term and preterm rabbits as a function of time after delivery. At delivery in the term rabbits, a concentration of about $2.4 \mathrm{mM}$ was found. Over the first $30 \mathrm{~min}$, this value decreased to about $1.8 \mathrm{mM}(P<$ $0.5)$. This was followed by an increase to $2.5 \mathrm{mM}$ at the 5 th $\mathrm{hr}(P$ $<0.05$ ). By the 7 th $\mathrm{hr}$ postpartum, the mean of the glucose concentration had returned to about $2.0 \mathrm{mM}$.

The whole blood glucose concentration in the preterm rabbits at delivery was almost equivalent to that of the term animals, but decreased to about $0.7 \mathrm{mM}(P<0.05)$ an hour later. From the 3 rd to the $4 \mathrm{th} \mathrm{hr}$, the concentration appeared stable at about $1.4 \mathrm{mM}$, but by the 6 th $\mathrm{hr}$ it was significantly lower, $0.7 \mathrm{mM}(P<0.05)$.

Immediately after delivery, the blood glucose of the preterm animals decreased to substantially lower levels than that of the term animal. However, both groups were able to reverse this trend by $\mathrm{l} \mathrm{hr}$ and actually increase the glucose concentration during the next $3 \mathrm{hr}$.

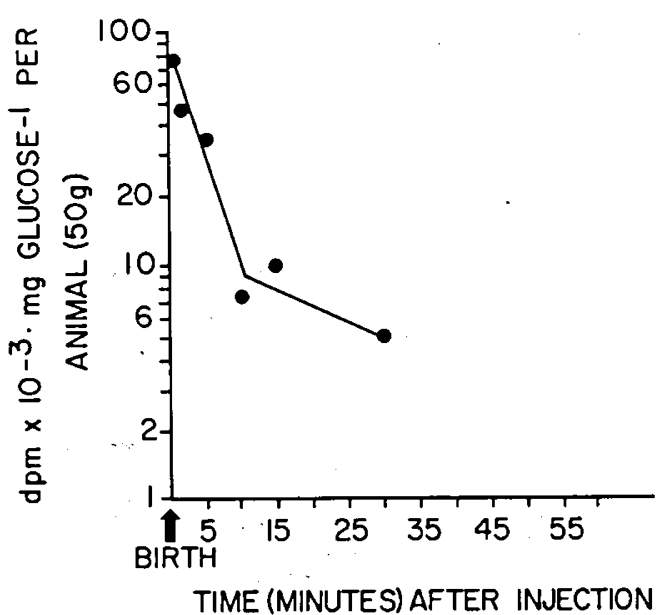

Fig. 3. Whole blood glucose specific radioactivity $\left(\mathrm{dpm} \times 10^{-3} \cdot \mathrm{mg}\right.$ glucose $^{-1} / 50 \mathrm{~g}$ animal) as a function of time (min) after iv injection of 0.5 $\mu \mathrm{Ci} \mathrm{L}-\left[1-{ }^{14} \mathrm{C}\right]$ lactate. Semilogarithmic plot of the means of the data expressed in Figure 5.

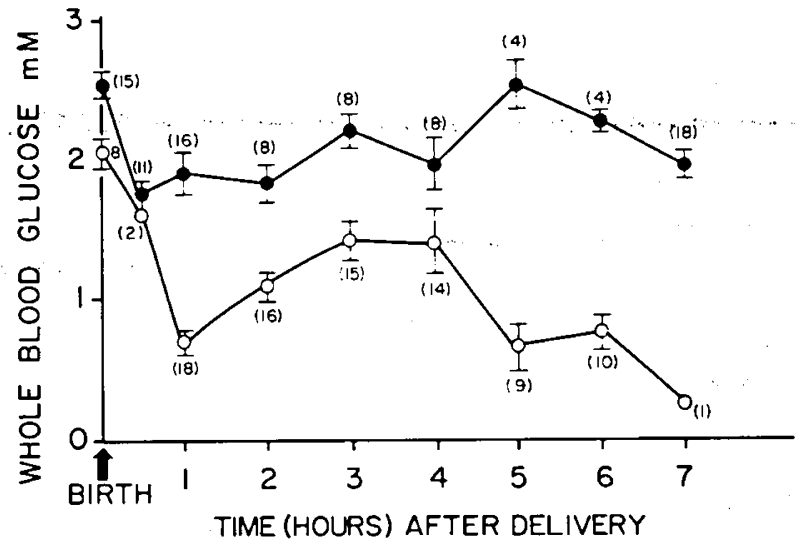

Fig. 4. Whole blood glucose concentration (mM) in 28.5 and 30.5 day gestational age rabbits as a function of time after delivery (hr). All data are expressed as the mean \pm SEM or the mean only. The number of animals is in parentheses. $(\Theta=30.5$ days, $O=28.5$ days $)$. 
Although the rate of utilization of glucose decreases due to the lower level of blood sugar (16), utilization does not stop completely and, therefore, a new source of of glucose is needed to maintain or to increase the level of blood sugar. The large decrease in blood glucose during the $1 \mathrm{st} \mathrm{hr}$ in the preterm animals suggests that an inability to reverse this decrease by glycogenolysis or gluconeogenesis may be responsible for the failure of some preterm animals to survive.

\section{WHOLE BLOOD LACTIC ACID}

Figure 5 shows the behavior of the whole blood lactic acid concentration as a function of time after delivery. The term animals possessed lactic acid concentrations at delivery of about $5.7 \mathrm{mM}$, but, by $1 \mathrm{hr}$ later, the concentration had decreased to $0.75 \mathrm{mM}$. The concentration remained at this level for the next 6 hr.

The lactate concentration in the preterm animal was initially as high as in the term animal. It was not until $2 \mathrm{hr}$ after delivery, however, that it reached the concentration found in the term aniamls at $1 \mathrm{hr}$. Between the 4th and $5 \mathrm{th} \mathrm{hr}$, a further small, but significant, decrease, $0.4-0.1 \mathrm{mM}(P<0.05)$, was observed in the preterm animals. These low levels are generally uncharacteristic of term or normal adult animals. Perhaps they are indicative of the diminution of hepatic glycogen in the preterm animal, which would result in low levels of circulating glucose and decreased glycolysis in certain tissues. Helmrath and Bieber (7) have also observed similar low levels of lactate in the blood of newborn piglets.

The slower rate of reduction of the blood lactate level in the preterm animal during the period immediately after birth and the concomitant extensive fall in blood glucose suggest the occurrence of a prolonged period of anaerobic glycolysis. This may be the result of slow oxygenation after delivery because of poor lung function in these animals (14). In addition, certain tissues produce lactate continually because they obtain energy exclusively by the glycolytic pathway. If lactate removal partly depends on gluconeogenesis in the term animal, absence of this pathway in the preterm animal may contribute to a low rate of clearance of blood lactate.

\section{HEPATIC GLYCOGENOLYSIS}

Figure 6 portrays the hepatic glycogen levels of the neonate as a function of time after delivery. The data from the term animals

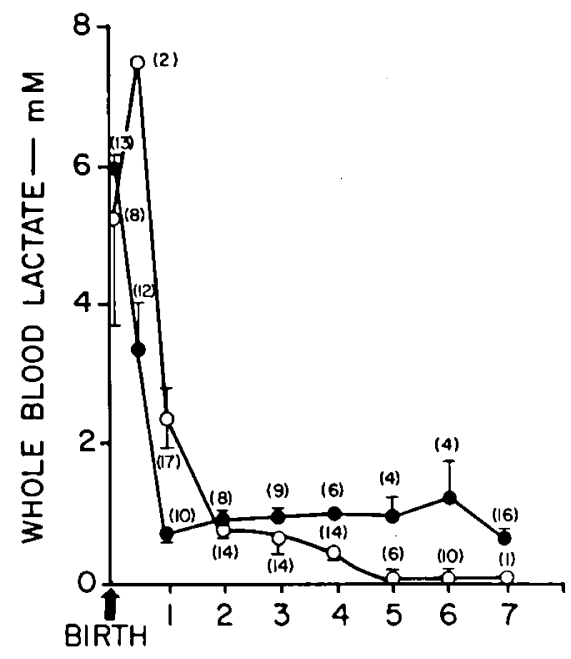

\section{TIME (HOURS) AFTER DELIVERY}

Fig. 5. Whole blood lactic acid concentration (mM) in 28.5 and 30.5 day gestational age rabbits as a function of time after delivery (hr). All data are expressed as the mean \pm SEM or the mean only. The number of animals is in parentheses. $(\Theta=30.5$ days; $\odot=28.5$.days $)$.

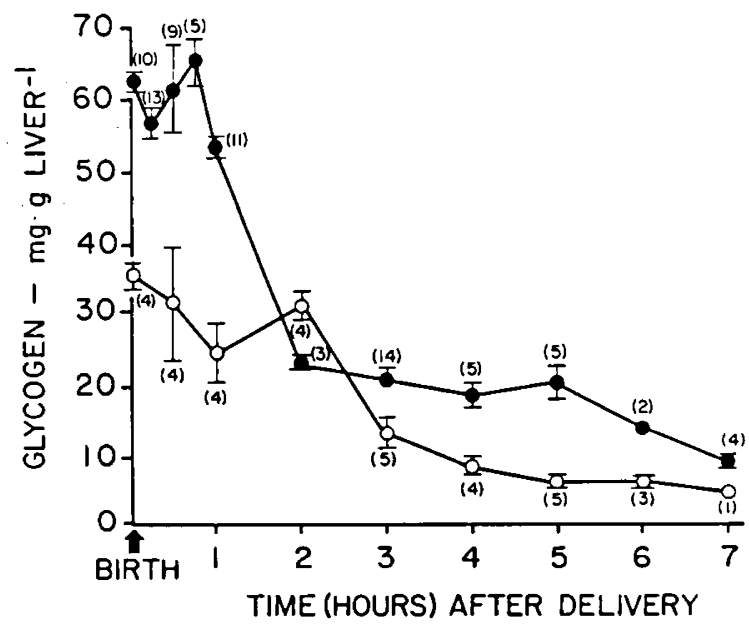

Fig. 6. Hepatic glycogen levels, $\mathrm{mg} \cdot \mathrm{g} \operatorname{liver}^{-1}$ as a function of time after delivery (hr) in 28.5 and 30.5 day gestational age rabbits. All data are expressed as the mean \pm SEM or the mean only. The number of animals is in parentheses. $(=30.5$ days, $O=28.5$ days $)$.

indicate that rapid glycogenolysis began at $1 \mathrm{hr}$, or less, after delivery and proceeded rapidly from the 1 st-2nd hour and that the concentration of glycogen reached a minimum value of 10 $\mathrm{mg} / \mathrm{g}$ liver, wet wt, at $7 \mathrm{hr}$ after delivery.

It is apparent from Figure 6 that the 28.5 day animals begin life with approximately $50 \%$ of the glycogen concentration found in the 30.5 day animals at delivery $(P<0.05)$, and that both groups may begin to mobilize glycogen slowly at delivery. At the end of the period studied, the glycogen concentrations are approaching the same value.

Even though the hepatic glycogen concentration in the preterm is only about one-half of the term level $(4,6)$, it does represent a reserve of carbohydrate and over the $1 \mathrm{st} 4 \mathrm{hr}$, about $57 \mathrm{mg}$ are released. This contrasts with the term rabbit which releases about $124 \mathrm{mg}$ the lst $2 \mathrm{hr}$. However, an increase in blood glucose is effected in both groups by the $2 \mathrm{nd} \mathrm{hr}$. Whether this increase is due to glycogenolysis alone remains to be established. This suggests that the preterm animal that fails to adapt has a substantially lower glycogen level than the preterm animals described here or is unable to release the glycogen, the blood sugar level will become very low and death will result.

\section{GLUCONEOGENESIS}

Table 1 contains the whole blood glucose specific radioactivity data from ${ }^{14} \mathrm{C}$-labeled precursor studies in term and preterm animals. All specific radioactivity data have been adjusted to a standard animal having a body weight of $50 \mathrm{~g}$. This adjustment allowed us to inject a standard dose of isotope $(0.5 \mu \mathrm{Ci} / 50 \mu \mathrm{l})$ without correcting dose for body weight. A $5 \mathrm{~min}$ labeling period before killing was allowed after each injection.

When $\mathrm{L}-\left[1-{ }^{14} \mathrm{C}\right]$ lactate was injected at delivery, term animals were capable of limited conversion of this radioactivity into whole blood glucose radioactivity. On the other hand, no radioactivity from lactic acid could be recovered in glucose when preterm animals were injected at delivery or at $1 \mathrm{hr}$ and killed 5 min later.

Because radioactivity from lactate was found in glucose immediately after delivery in term rabbits (Fig. 2,3), one concludes that gluconeogenesis is somewhat functional at delivery and might possibly be needed to replace the maternal source of carbohydrate. On the other hand, limited gluconeogenesis and glycogenolysis together did not prevent a fall in blood glucose the Ist hr (Fig. 4).

Upon a cursory examination of the results of $\mathrm{L}-\left[\mathrm{l}^{14}\right]$ lactate injection, one might expect formation of a higher specific radioactivity glucose at $1 \mathrm{hr}$ than at the 0 hour injection because the blood lactate and glucose concentrations decreased significantly during that hour (Fig. 4). That this did not occur may be explained by assuming that the lactate flux through the pathway is decreased 
Table 1. Glucose specific radioactivity recovered from whole blood

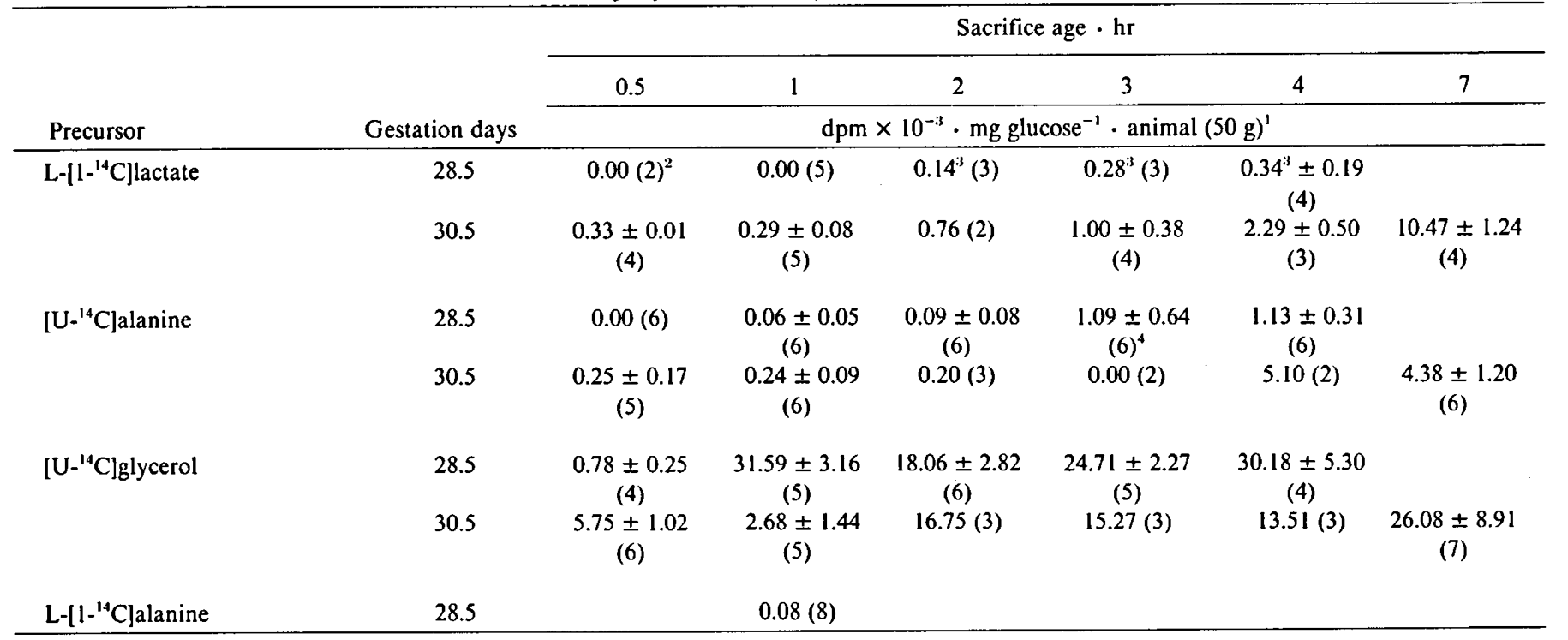

\footnotetext{
1 Values are mean \pm SEM or mean only.

2 Number of animals.

"Mean includes 2 values of 0.00 .

${ }^{4}$ Mean includes 3 values of 0.00 .
}

at $\mathbf{l ~ h r}$ because of the decreased concentration. If, indeed, there is a high flux at delivery, it may be responsible for some of the decrease in lactate concentration during the hour after delivery. A quantitative estimate of the extent of the conversion of lactate to glucose is not possible from these data.

In term animals the glucose specific radioactivity at $5 \mathrm{~min}$ after injection of $\mathrm{L}-\left[1-{ }^{14} \mathrm{C}\right]$ lactate showed a tendency to be higher with time after delivery, reaching a value of about $1000 \mathrm{dpm} \cdot \mathrm{mg}$ glucose $^{-1}$. animal $(50 \mathrm{~g})$ by the $3 \mathrm{rd} \mathrm{hr}$ and $10,000 \mathrm{dpm}$ by the 7 th $\mathrm{hr}$ (Table 1 ). In the preterm animals, glucose specific radioactivity could not be measured with certainty at any time during the period studied, even though some ${ }^{14} \mathrm{C}$-glucose was recovered from individual animals.

It appears that the preterm animal is incapable of significant conversion of lactate to glucose even at $4 \mathrm{hr}$ old. Apparently this is not critical for adaptation, because many of the preterm animals are capable of surviving this period. Because liver glycogen is essentially depleted (Fig. 6), development of gluconeogenesis after $4 \mathrm{hr}$ of age appears mandatory in order to prevent severe hypoglycemia.

Radioactivity from $\left[\mathrm{U}-{ }^{14} \mathrm{C}\right]$ alanine was recovered in glucose from both gestational age groups at all the times studied, except immediately after delivery in the preterm animals (Table 1). Because essentially no radioactivity was recovered from preterm animals injected with $\mathrm{L}-\left[1-{ }^{14} \mathrm{C}\right]$ lactate at $1 \mathrm{hr}$, these results seemed incongruous. This difference was resolved when eight preterm animals received an iv injection of $\mathrm{L}-\left[1-{ }^{14} \mathrm{C}\right]$ alanine $\mathrm{I} \mathrm{hr}$ after delivery. After a 5 min labeling period, no radioactivity could be recovered in glucose, indicating that radioactivity in glucose from $\left[\mathrm{U}-{ }^{14} \mathrm{C}\right]$ alanine probably arose via the Krebs cycle rather than directly from gluconeogenesis. This indicated that the preterm rabbit converts no alanine to glucose the $1 \mathrm{st} 4 \mathrm{hr}$ after delivery. It also suggests that pyruvate carboyxlase is relatively inactive as compared to pyruvate dehydrogenase or the enzymes of the Krebs cycle and that phosphoenolpyruvate carboxykinase is active. Also, alanine aminotransferase may be inactive in the preterm animal immediately after delivery, but active by $1 \mathrm{hr}$.

The most striking changes in glucose specific radioactivity were observed when $\left[\mathrm{U}_{-}^{-4} \mathrm{C}\right]$ glycerol was used. When term animals were injected with this precursor at delivery, about $5000 \mathrm{dpm} \cdot \mathrm{mg}$ glucose $\mathrm{e}^{-1}$ animal $(50 \mathrm{~g})$ were obtained from whole blood $5 \mathrm{~min}$ later. This value increased to about $50,000 \mathrm{dpm} \cdot \mathrm{mg}$ glucose $^{-1}$. animal $(50 \mathrm{~g})$ by the $2 \mathrm{nd} \mathrm{hr}$ postpartum. The data obtained from the preterm animals were quite different. At $5 \mathrm{~min}$ after delivery about $800 \mathrm{dpm} \cdot \mathrm{mg}$ glucose $\mathrm{g}^{-1}$ - animal $(50 \mathrm{~g})$ could be recovered after injection of $\left[\mathrm{U}-{ }^{14} \mathrm{C}\right]$ glycerol, but $1 \mathrm{hr}$ after delivery, this value was found to be about $32,000 \mathrm{dpm} \cdot \mathrm{mg}_{\text {glucose }}^{-1} \cdot \operatorname{animal}(50 \mathrm{~g})$.

At all time periods studied, there appears to be conversion of labeled glycerol to glucose. However, the blood concentration of this substrate is probably about $1 / 60$ the concentration of lactate, so that a high specific radioactivity product may be the result of a high specific radioactivity substrate and of a relatively rapid flux through the gluconeogenic pathway. Gluconeogenesis from glycerol may produce some glucose during the 1 st $2 \mathrm{hr}$ after delivery. This contribution may partially explain the rise of blood sugar after the initial decline. In the preterm animals that survived, there appears to be no defect in gluconeogenesis from glycerol as compared to the term animals. On the other hand, in nonsurviving animals, glycerol levels may be extremely low and would not be able to contribute very much toward glucose synthesis or there may be a defect in the gluconeogenic pathway in these animals.

\section{REFERENCES AND NOTES}

1. Bartels, H.: Metabolite levels reflecting changes in liver energy metabolism during the neonatal period. Biol. Neonaet., 24: 32 (1974).

2. Blazquez, E., Sugase, T., Blazquez, M., and Foa, P. P.: Neonatal changes in the concentration of rat liver cyclic AMP and of serum glucose, free fatty acids, insulin, pancreatic, and total glucagon in man and in the rat. J. Lab. Clin. Med., 83: 957, (1974)

3. Bossi, E., and Greenberg, R. E.: Sources of blood glucose in the rat fetus. Pediatr. Res., 6: 765 (1972).

4. Dawkins, M. J. R.: Glycogen synthesis and breakdown in fetal and newborn rat liver. Ann. N. Y. Acad. Sci, III: 203 (1973).

5. Girard, J. R., Cuendet, G. S., Marliss, E. B., Kervran, A., Rieutort, M., and Assan, R.: Fuels, hormones, and liver metabolism at term and during the early postnatal period in the rat. J. Clin. Invest., 52: 3190 (1973).

6. Greengard, O., and Dewey, H. R.: The premature deposition or lysis of glycogen in livers of fetal rats injected with hydrocortisone or glucagon. Dev. Biol., 21: 452 (1970)

7. Helmrath, T. A., and Bieber, L. L.: Development of gluconeogenesis in neonatal pig liver. Am. J. Physiol., 227: 1306 (1974).

8. Mattenheimer, .: Enzymatic determination of metabolites. In: Micromethods for the Clinical and Biochemical Laboratory, p. 97 (Ann Arbor Science Publishers, Inc., Ann Arbor, 1971).

9. Mersmann, H. J.: Glycolytic and gluconeogenic enzyme levels in pre- and postnatal pigs. Am. J. Physiol., 220: 1297 (1971).

10. Pearce, P. H., Buirchell, B. J., Weaver, P. K., and Oliver, I. T.: The development of phosphopyruvate carboxylase and gluconeogenesis in neonatal rats. Biol. Neonate., 24: 320 (1974).

11. Philippidis, H., and Ballard, F. J.: The development of gluconeogenesis in rat liver, effects of glucagon and ether. Biochem. J., 120: 385 (1970). 
12. Philippidis, H., and Ballard, F. J.: The development of gluconeogenesis in rat liver, experiments in vivo. Biochem. J., 112:651 (1969).

13. Roehrig. K. L., and Allred, J. B.: Direct enzymatic procedure for the determination of liver glycogen. Anal. Biochem., 58: 414 (1974).

14. Shelley, H. J.: Glycogen reserves and their changes at birth and in anoxia. $\mathrm{Br}$. Med. Bull., 17: 137 (1961).

15. Snedecor, G. W., and Cochran, W. G.: The comparison of two samples. In: Statistical Methods, 6th ed., p. 114 (The lowa State University Press, Ames, Iowa, 1972).

16. Snell, K., and Walker, D. G.: Glucose metabolism in the newborn rat, studies in vivo. Biochem. J., 132: 739 (1973).

17. Snell, K., and Walker, D. G.: Glucose metabolism in the newborn rat, hormonal effects in vivo. Biochem. J., 134: 899 (1973).

18. Swiatek, K. R.: Development of gluconeogenesis in pig liver slices. Biochem Biophys. Acta 252: 274 (1971).
19. Vernon, R. G., and Walker, D. G.: Glucose metabolism in the developing rat, studies in vivo. Biochem. J., 127: 521 (1972).

20. Vernon, R. G., and Walker. D. G.: Gluconeogenesis from lactate in the developing rat. studies in vivo. Biochem. J., 127: 531 (1972).

21. Yeung. D., Stanley, R. S., and Oliver, I. T.: Development of gluconeogenesis in neonatal rat liver. Biochem. J., 105: 1219 (1967).

22. L. M. Mazzuckelli for his technical assistance and Jeri Stewart for her assistance in preparation of the manuscript.

23. Portions of this data were presented at the American Chemical Society Annual Meeting. September 10, 1974. Atlantic City, NJ USA.

24. This research was supported by The William K. Warren Medical Research Center, Tulsa, OK. (USA).

25. LeRoy C. Mims, M.D., 1923 S. Utica Ave., Tulsa, OK 74104 (USA)

26. Received for publication February 27, 1978.

27. Accepted for publication May 3, 1978. 